\title{
ВОЗМОЖНОСТИ АКТИВИЗАЦИИ УЧЕНИКОВ ПРИ ОБУЧЕНИИ ИНОСТРАННОМУ ЯЗЫКУ С ИСПОЛЬЗОВАНИЕМ ИКТ (С УЧЁТОМ РКИ)
}

\author{
Вероника Капланова
}

\section{POSSIBILITIES OF ACTIVATING PUPIS IN LEARNING A FOREING LANGUAGE USING ICT (WITH REGARD TO THE RUSSIAN LANGUAGE AS A FOREIGN LANGUAGE)}

\author{
Veronika Kaplanova
}

\begin{abstract}
Резюме: В данной статье рассматриваются возможности использования некоторых активных методов и организационных форм обучения в контексте использования информационных и коммуникационных технологий. Активные методы и подходы анализируются с теоретической точки зрения, особенно в отношении решения проблем, конструирования новых знаний, приобретения коммуникативной и межкультурной компетенции, мотивации, сотрудничества и развития личности ученика. Здесь также описываются их преимущества и недостатки или ограничения. Далее в статье представлены практические примеры непосредственно для преподавания русского языка как иностранного.
\end{abstract}

Ключевые слова: Информационные и коммуникационные технологии, активные методы обучения, русский язык как иностранный.

\begin{abstract}
This article deals with the possibilities of using selected activating methods and organizational forms of teaching in the context of the use of information and communication technologies. Activating methods are analysed from the theoretical point of view, especially with regard to problem solving, constructing new knowledge, acquiring communication and intercultural competence, motivation, cooperation and the development of the pupil's personality. It also describes their advantages and disadvantages or limits. Additionally, the article presents practical examples useful for lessons of Russian as a foreign language.
\end{abstract}

Key words: Information and communication technologies, activating teaching methods, Russian as a foreign language.

DOI: $10.14712 / 9788076032088.7$

Информационные и коммуникационные технологии (ИКТ) являются в современном глобализованном мире неотъемлемой частью жизни большинства людей, поэтому они логически являются также составной частью образования, где при правильном использовании могут быть очень полезным помощником для учеников и преподавателей и способствовать лучшему пониманию, практике и владению обучаемого материала. Четкость мультимедиа также значительно облегчает формирование мнений и выводов или обнаружение контекста. Аудиовизуальные материалы помогают создать подходящие условия, необходимые для мыслительного процесса, мотивации ученика и активизации.

Рассматривая активизацию учеников в обучении, необходимо подумать о её влиянии на личность ученика и его гармоничное развитие, для которого деятельность является одной из 
важных предпосылок. «Под активностью мы подразумеваем увеличение усилий, мобилизацию психических сил и вовлеченность в данную деятельность. Если мы говорим об учебной деятельности учащихся, то речь идет, в основном, о создании позитивного отношения к школьной работе, которое проявляется, например, в готовности ученика выполнять задачи, связанные с преподаванием». (Mazáčová 2014, 56, перевод автора)

ИКТ могут служить для учителей отличным средством активизации учеников в классе и вне его. Что касается активных методов, «это не конкретные методы обучения, но в основном любой метод, который надлежащим образом и осмысленно включен в обучение, может значительно поддержать, активизировать учебную деятельность учеников и процессы обучения. Основой для применения активных методов является продумывание, организация, управление и оценка обучения таким образом, чтобы реализация, достижение цели обучения, осуществлялась главным образом посредством собственной познавательной деятельности учащихся. ... Это методы, которые обеспечивают ученикам активность, поддерживают индивидуальные и коллективные стратегии обучения, создают пространство для инициативной и творческой деятельности, приобретения личного опыта для самореализации ученика, и способствуют снижению негативных эмоций в школьной среде, таких как беспокойство, страх или скука, и которые, естественно, приводят к самоконтролю и ответственности учеников». (Mazáčová 2014, 55, 58, перевод автора)

По сравнению с традиционными методами, при использовании активных, создание знаний (построение) и эвристические методы (решение проблем) используются гораздо чаще. Преподаватель должен всегда иметь в виду ученика и максимально активизировать его деятельность в учебном процессе. Средства активизации, в которых ИКТ могут использоваться надлежащим образом, включают кооперативное обучение, методы, основанные на деятельности, и дидактические игры.

Кооперативное обучение как комплексный метод обучения является одной из наиболее распространенных педагогических инноваций и «основано на сотрудничестве людей в решении более сложных задач. Исполнители должны быть в состоянии разделить социальные роли, спланировать всю деятельность, разделить частичные задачи, научиться консультировать, помогать координировать усилия, контролировать друг друга, разрешать частичные споры, объединять частичные результаты в одно целое, оценивать преимущества отдельных членов и т. д.» (Průcha, Walterová, Mareš 2013, 107, перевод автора). Целью обучения является также приобретение способности сотрудничать в качестве ключевой компетенции. Состязательность, с другой стороны, намеренно ограничивается.

Ученики могут работать над заданием в группах. Для сбора информации на общую тему можно пользоваться интернетом. Они могут использовать текстовые и графические редакторы для обработки полученной информации, а затем делиться общим результатом со своими одноклассниками посредством приложений для создания презентации или облачного хранилища. В приложении (например, Google Docs) можно напрямую создавать документы, совместно работать над ними и получать к ним доступ из любого места. Обмен документами позволяет, например, также распространённый Office 365. Интернет-сообщения, фильмы, видеозаписи и т. д. являются подходящим стимулом для группового обсуждения. Далее ученики могут вместе создавать интеллект-карты с помощью ИКТ (например, приложение Spicynodes и т. д.).

В преподавании иностранного языка одной из основных целей (не единственной) является приобретение коммуникативной компетенции. ИКТ могут в рамках кооперативного 
обучения служить средством коммуникации (электронная почта, программы мгновенного обмена текстовыми сообщениями, позволяющие (групповые) голосовые и видеозвонки ${ }^{1}$ на смартфоне, планшете, ноутбуке и т. д.). Жанг (Zhang онлайн) расширяет использование ИкТ в кооперативном обучении также для удовлетворения потребностей синхронного образования вне классной комнаты. Можно использовать виртуальные конференции, где все ученики могут активно работать, делиться экраном, хранить информацию в виртуальном хранилище. лМС 2 позволяют писать, редактировать и просто публиковать созданные документы. Учителя имеют доступ к данным, могут назначать задания, контролировать прогресс или комментировать.

Следующей областью для подходящего использования ИКТ является обучение, основанное на собственной деятельности и опыте, следующее из тезиса Дж. Пиаже о том, что обучение происходит между субъектом и миром, то есть оно не начинается со школы и не ограничивается ей. Естественно, существует противоречие между тем, что ученик уже знает, и новыми знаниями и навыками, которые он должен приобрести. Ученик добивается прогресса, когда он сам чувствует это напряжение, активно преодолевает противоречия и «строит новые структуры, которые означают более высокий уровень знаний. Поэтому он внутренне активен». Таким образом, это является альтернативой рутинному словесно-иллюстративному обучению. (Skalková 2007, 138-140, перевод автора)

Приёмы ориентированы на ученика и его способности. Приобретение знаний и навыков не является основной целью. Акцент делается на решение проблем, предоставление возможности творческой активности, самостоятельного мышления иобучения с участием чувств. Ученик максимально независим в учебном процессе. Даже ученики разных когнитивных стилей могут учиться вместе. Учитель только направляет обучение. (Nečasová in Nečasová, Podhajská 2006, 21-22)

«Деятельностный подход к обучению может применяться на всех этапах обучения, при овладении всеми языковыми средствами и речевыми умениями. Тем не менее, он особенно подходит для методологической обработки тематических блоков». (Nečasová in Nečasová, Podhajská 2006, 21, перевод автора)

ИКТ могут приблизить или симулировать мир и опыт собственных действий и помочь в создании задач, которые ведут к развитию ученика. С их помощью учитель может создавать дидактические ситуации, поддерживающие активное взаимодействие ученика с учебным материалом и, таким образом, вызывая его интерес. Они знакомят учеников с комплексными учебными ситуациями. (Skalková 2007, 140) Для того являются подходящими виртуальные экскурсии по музеям и галереям (например, Третьяковская галерея в Москве в Google Arts and Culture), электронные книги на определенную тему из русской культуры, создание комиксов о событиях в истории России, работа с картой (включая, например, Google Street View) и т. д. Современные технологии могут предоставить учащимся источник эмоционального опыта и мотивировать их к дальнейшему изучению.

Елинек (Jelínek in Nečasová, Podhajská 2006, 14) упоминает еще один пример, когда ученики учатся по деятельности, в случае межкультурно ориентированного обучения посредством тандемного обучения, при котором ученики одновременно преподают друг другу два языка и две культуры. Это может проводиться через общение с помощью Whatsapp и других программ, обеспечивающих телефонные и видеозвонки. Чех может учить русский язык, русский

\footnotetext{
${ }^{1}$ Peer-to-peer

${ }^{2}$ LMS (Learning Management Systems)
} 
может учить чешский - оба в своих странах, без необходимости путешествия. Они способствуют формированию друг у друга формированию межкультурной и социокультурной компетенций.

ИКТ можно соответствующим образом использовать для активизации в проектном методе, или же в проектном обучении. «Проектный метод - это метод обучения, при котором ученики должны самостоятельно разрабатывать определенные проекты и приобретать опыт посредством практической деятельности и экспериментов. Проекты могут принимать форму интегрированных тем, практических проблем из реальной жизни или практических действий, ведущих к созданию продукта, художественного или словесного продукта. ... Проектное обучение - это обучение, основанное на методе проекта» (Průcha, Walterová, Mareš 2013, 184, перевод автора). Маняк и Швец (Maňák, Švec 2003, 168, перевод автора) описывают проект как «сложную практическую задачу (проблему, тему), связанную с реальностью жизни, которая должна быть решена теоретическими и практическими действиями, которые ведут к созданию адекватного продукта». Проектное обучение принадлежит к комплексным методам обучения.

Точно так же Нечасова (Nečasová in Nečasová, Podhajská 2004, 25) считает, что в конце каждого проекта должен быть практический конкретный результат. Такой вывод может представлять собой альбом в электронном виде, видеозапись, электронный коллаж, презентации, комиксы, публикации результатов на веб-сайте школы и т. д.

Что касается обучения иностранным языкам, то, согласно Нечасовой (Nečasová in Nečasová, Podhajská 2004, 25), задача или проблема, решаемая в рамках проекта, должна быть интересной для учеников, но в то же время постоянно необходимо учитывать исходные точки, которые являются обязательными для обучения (например, основная образовательная программа). Обучение должно быть максимально приближено к условиям реального общения.

Примером использования ИКТ в проектном обучении является долгосрочный проект планирования групповой поездки всего класса в Москву. Ученики могут быть разделены на группы, и каждая группа может работать над своим заданием, в идеале исключительно в русскоязычном интерфейсе и с русскоязычными веб-сайтами. Задачи, которые ученики выполняют с помощью современных технологий, могут быть следующими (конечно, они могут быть изменены или дополнены любым способом):

- Поиск вариантов транспорта и бронирования выбранного типа на подходящую дату (включая, например, информацию о ширококолейный железной дороге в случае железнодорожных перевозок, названия российских аэропортов и т. д.).

- Поиск вариантов размещения и его бронирование.

- Поиск основной информации о городе.

- Выбор памятников, которые класс посетит (включая православные церкви и их особенности по сравнению с христианскими церковными памятниками, такими как головной убор женщин, иконостас и т. д.).

- Поиск и планирование другой программы (посещение театра - например, Большой театр, его история, интересные факты, текущая афиша; галереи - например, планирование экскурсии с помощью предыдущего виртуального тура и т. д.).

- Размышление о возможностях, как класс будет перемещаться по городу (план московского метро, страницы с историей метро, фотографии, интересные факты; что такое маршрутки и т. д.).

- Планирование прогулок по городу (можно использовать, например, Google Street View). 
- Поиск информации о российской валюте (её название, курс, кто отображается на банкнотах и т. д.).

- Поиск советов по сувенирам (что характерно для России - матрёшки, цветные шарфы и т. д.).

- Выбор одежды (по прогнозу погоды на российских метеорологических серверах; одежда с учетом посещаемых памятников и культурных мероприятий).

Прежде чем класс избирает любой вариант, группы могут представить свои выводы с помощью средств электронной презентации, а затем класс обсудит возможности. Учитель выступает в роли советника.

В рамках проекта, который помогает устранить энциклопедизм и укрепляет междисциплинарные отношения, ученики узнают много нового о России, её истории и культуре, а также научатся справляться с практическими занятиями (бронирование гостиницы и транспорта онлайн, работа с интерактивной картой, поиск театральной афиши, подходящей одежды и многое другое). Ученики используют свои имеющиеся знания и опыт, чтобы их применять.

Другие положительные стороны метода проекта включают развитие ключевых компетенций, неискусственный характер темы работы, подготовку к решению проблем в повседневной жизни, жизненные отношения, спонтанный интерес и собственные усилия ученика, упорство в преодолении препятствий, стремление к достижению целей, основанных на внутренней мотивации, возможность найти свой собственный путь как приобрести знания и навыки, удовлетворение собственной работой, использование полученных знаний, которые не являются изолированными, но имеют интегративную форму (развитие междисциплинарных отношений) и, что не менее важно, межкультурное и социальное обучение. (Hausenblas, Koštálová, Mazáčová 2010 онлайн; Dvořáková 2009, 36; Dömischová 2011, 42) Ученики работают с аутентичными материалами (сайтами на иностранных языках) так же, как и в реальной жизни. (Brandl, 2002, с. 94) Проектное обучение, соотв. его результат укрепляет уверенность и независимость ученика. (например, Stoller 2016, 20; Fried-Booth in Fragoulis 2009, 113)

Недостаток проектного обучения заключается в том, что действительно спонтанные проблемы возникают лишь изредка. Проектное обучение занимает много времени и должно быть тщательно спланировано. Такое обучение может быть также слишком сложным как для слабых учеников, так и для учителей, потому что оно требует знаний и навыков вне их специальности в узком смысле (включая компьютерную грамотность). (Dvořáková 2009, 36; Nečasová in Nečasová, Podhajská 2004, 33)

Таким же образом, ИКТ могут быть полезными при использовании активных эвристических методов, таких как проблемное обучение. Например, ученикам может быть дано задание ответить на вопрос с помощью интернета (такие специальные упражнения для поиска и обработки информации из интернета включены, например, в учебник русского языка Поехали $)^{3}$, почему на русской Пасхе яйца окрашиваются в красный цвет, или самостоятельно найти пасхальный рецепт. Затем яйца можно окрашивать, например, с использованием натуральных красителей, и пищу можно готовить и есть вместе, создавая тем самым желаемую связь между проектным и проблемным обучением.

\footnotetext{
${ }^{3}$ Авторы Г. Жофкова, К. Ейбенова, 3. Липтакова, Й. Шарох, издательства Авлбра
} 
Для ситуационных методов подходит возможность простой записи на мобильные телефоны. Класс может, например, записать свою драматизацию русской сказки или комментированного показа мод, который они организуют при изучении темы одежда и цвета.

Старшим и младшим ученикам также нравятся соревнования, викторины, игры, кроссворды и другое. Уже Ян Амос Коменский подчеркивал важность игры, которая является значительным мотивирующим элементом в обучении. Игра, несомненно, имеет свое место в образовательном процессе даже сейчас. С небольшим преувеличением можно сказать, что ученики учатся посредством игры, даже не зная об этом. Кроме того, игры поддерживают творческий потенциал ученика.

Благодаря интерактивному дисплею, интерактивной доске и планшетам учащиеся могут соревноваться онлайн. Они могут играть в интернет-скрэббл (например, на http://iharsw.login.by/wordsru/) и использовать различные аппликации для тренировки словарного запаса в форме игры, которые подходят не только для школьного, но и для внеклассного использования. ИкТ помогает учителям создавать такие игры, как бинго, кроссворды, восьмиугольники, адаптированные к тематике лексики и т. д. (например, на https://www.toolsforeducators.com/bingo/).

Использование ИкТ в рамках применения активных методов имеет свои плюсы, но, конечно, также свои ограничения. По словам Мазачовой (Mazáčová 2014, 57-58), преимущество активных методов, несомненно, заключается в том, что они стимулируют интерес учащихся к обучению, поддерживают независимость, гибкость, творческий подход и саморазвитие ученика. Они также помогают сделать положительную самооценку, потому что каждый ученик может внести свой вклад. Активные методы также способствуют развитию дружеских отношений в группах и классах, умению коммуникации, саморефлексии и способности преодолевать препятствия. Атмосфера в таком обучении определяется игривостью, минимизирующей мандраж или страх перед ошибкой, и свободой решения и проявления. Дополнительная ценность интернета и других инструментов ИКТ заключается в том, что они являются отличным средством перехода «из школьной среды в аутентичную среду естественного языка со всеми культурными аспектами». (Zahradníková in Nečasová, Podhajská 2004,111 , перевод автора) В общем можно сказать, что современные технологии ученикам близки и работа с ними (и следовательно изучение языка и реалий) для них привлекательна.

Однако активные методы, какими бы полезными они ни были, не могут заменить систематическое обучение предметам. Ученики уже должны иметь по теме определённые знания и должны быть способны их развивать. Учитель должен выбрать активные методы только, если они имеют смысл с учетом темы, возраста учеников и характера группы. Другим недостатком является то, что, если они применяются слишком часто, то ученикам может стать скучно. Скука вызывает недисциплинированность в классе. Доступность интернета или мобильного телефона может быть также отвлекающий.

Существуют также трудности с точки зрения учителя, который, включая их в преподавание, "должен избавиться от директивного способа управления и, таким образом, отказаться от доминирующего положения в классе. Эти методы также требуют больше учебного времени и их труднее организовать и подготовить». (Mazáčová 2014, 57, перевод автора) Использование технологий также предъявляет повышенные требования к грамотности учителя в области ИКт.

И последнее, но не менее важное: в случае активизации учеников с помощью ИкТ необходимо упомянуть технические проблемы с неработающим оборудованием, сбои 
подключения к интернету и т. д. Технические дефекты могут полностью разрушить даже самую тщательно отобранную подготовку учителя к преподаванию и таким образом и урок или даже весь комплексный проект класса.

В заключение хотелось бы подчеркнуть, как и следует из вышеизложенного текста статьи, что ИКТ можно успешно применять в рамках разных активных методов и тем помогать ученику приобрести не только знания и навыки, касающиеся русского языка, и межпредметный контекст, а также развивать его личность. Тем образом их использование в обучении может быть большим преимуществом, но, конечно, также имеет свои и ограничения, определенные именно требованиями ученика, спецификами класса, личностью преподавателя, техническими средствами, целью и организационными формами обучения, которые учителю всегда необходимо тщательно учитывать.

\section{Использованная литература / References}

\section{Печатные источники:}

DÖMISCHOVÁ, I. (2011): Projektová výuka: moderní strategie vzděláváni v České republice a německy mluvících zemích. Olomouc: Univerzita Palackého v Olomouci, 2011. 214 c. ISBN 978-802-4429-151. DVOŘÁKOVÁ, M. (2009): Projektové vyučování v české škole: vývoj, inspirace, současné problémy. Praha: Karolinum, 2009. 158 c. ISBN 978-802-4616-209.

MAŇÁK, J., ŠVEC, V. (2003): Výukové metody. Brno: Paido, 2003. 219 c. ISBN 80-7315-039-5.

MAZÁČOVÁ, N. (2014): Vybrané problémy obecné didaktiky. Praha: Univerzita Karlova, Pedagogická fakulta, 2014. 93 c. ISBN 978-80-7290-677-2.

NEČASOVÁ, P., PODHAJSKÁ, E. (2006): Činnostní pojetí vyučování cizím jazykům: [sborník příspěvků z konference ... konané 30. záŕí 2004 na Univerzitě Karlově v Praze - Pedagogické fakultě]. Praha: Univerzita Karlova, Pedagogická fakulta, 2006. 124 c. ISBN 80-7290-281-4.

PRŮCHA, J., WALTEROVÁ E., MAREŠ, J. (2013) Pedagogický slovník. 7., aktualiz. a rozš. vyd. Praha: Portál, 2013. 400 c. ISBN 978-80-262-0403-9.

SKALKOVÁ, J. (2007): Obecná didaktika: vyučovací proces, učivo a jeho výběr, metody, organizační formy vyučování. Praha: Grada, 2007. Pedagogika (Grada). 328 c. ISBN 978-80-247-1821-7.

STOLLER, F. (2006): Establishing a Theoretical Foundation for Project-Based Learning in Second and Foreign Language Contexts. Project-based second and foreign language education: past, present, and future.

Greenwich, Conn.: Information Age Pub., 2006, c. 19-40. ISBN 9781593115067.

\section{Онлайн-источники:}

BRANDL, К. (онлайн): The integration of internet-based reading materials into the foreign language curriculum: From teacher- to student-centered approaches. Language Learning \& Technology: A refereed journal for second and foreign language scholars and educators September 2002, 6(3), 87-107. DOI: 10125/25178. ISSN 1094-

3501. [онлайн]. Режим доступа: https://www.lltjournal.org/item/2408 [дата обращения: 29.04.2019]

FRAGOULIS, I. (онлайн): Project-Based Learning in the Teaching of English as A Foreign Language in Greek Primary Schools: From Theory to Practice. English Language Teaching [online]. Beaver Creek (Ontario, Canada): Canadian Centre of Science and Education, 2009, September 2009, 2(3). 113-119. ISSN 1916-4750. [онлайн]. Режим доступа: https://files.eric.ed.gov/fulltext/EJ1083088.pdf [дата обращения: 29.04.2019].

HAUSENBLAS, O., KOŠŤÁLOVÁ H., MAZÁČOVÁ N. (онлайн): Nové metody výuky. Praha: Verlag Dashöfer, 2010. [онлайн]. Режим доступа: file:///C:/Users/User/Downloads/onlibped0115.pdf [дата обращения: 11.06.2020] ZHANG, Y. (онлайн): Cooperative Language Learning and Foreign Language Learning and Teaching. Journal of Language Teaching and Research. Academy Publication, 2010, 1(1), 81-83. DOI: 10.4304/jltr.1.1.81-83. ISSN 1798-4769. [онлайн]. Режим доступа: http://www.academypublication.com/issues/past/jltr/vol01/01/12.pdf [дата обращения: 23.04.2019]. 


\section{Профиль автора:}

Вероника Капланава, магистр

Научные интересы: выпускница Педагогического факультета Карлова университета в Праге - магистерской программы преподавания английского и русского языка для средней школы. Сейчас заочная аспирантка кафедры русистики и лингводидактики, там же. В своей диссертации она занимается преподаванием русского языка с помощью Икт.

e-mail: veronika.kaplanova@gmail.com

Место работы: Юникорн Юниверсити, Прага, В Капсловне 2767/2, 130 00, Чешская Республика

\section{Author's profile:}

Mgr. Veronika Kaplanová

Scientific interests: graduated from the Faculty of Education, Charles University in Prague, specialization of teaching English and Russian at the secondary school. At present she is an external student of a PhD programme at the Department Russian Studies and Language Teaching Methodology. Her dissertation focuses on the use of ICT for teaching Russian.

e-mail: veronika.kaplanova@gmail.com

Place of work: Unicorn University, V Kapslovně 2767/2, 13000 Praha 3, Czech Republic 